\title{
Comparison of Various Wet-Running Multi-Plate Clutches with Paper Friction Lining with Regard to Spontaneous Damage Behavior
}

\author{
T. Schneidera,*, A.B. Bedrikow ${ }^{a}$, K. Völkela, H. Pflaumª, K. Stahla \\ ${ }^{\mathrm{a}}$ Gear Research Centre (FZG), Technical University of Munich, 85748 Garching, Germany.
}

\begin{abstract}
Keywords:
Wet friction clutch

Spontaneous damage

Hot spots

Paper friction lining

Multiple plate clutch
\end{abstract}

* Corresponding author:

Thomas Schneider

E-mail: schneider@fzg.mw.tum.de

Received: 22 October 2020

Revised: 18 November 2020

Accepted: 5 January 2021

\begin{abstract}
A B S T R A C T
Wet-running multi-plate clutches fulfill a major safety-relevant role in drive trains and, as a result, damage to and failure of the clutch system must be strictly avoided, especially spontaneous damage. This paper deals with spontaneous damage to wet-running multi-plate clutches with paper friction lining with respect to spontaneous damage behavior. The paper presents a comparison method, by means of which the load-carrying capacity of various multi-plate clutches can be compared with regard to spontaneous damage based on experimental data and recommendations can be formulated. The experiments were performed on six different clutch variants, and the results were examined for significant differences. Various statistical tools were used to detect statistically significant variations. The experiments showed that higher load levels have a greater dispersion of the measured values, thus making comparisons more difficult. In the clutch variants investigated, significant changes in spontaneous damage behavior could only be detected when the cooling plate thickness or the carbon content was changed.
\end{abstract}

(C) 2021 Published by Faculty of Engineering

\section{INTRODUCTION}

Wet-running multi-plate clutches and brakes are essential machine elements in drive technology. They can be engaged under differential speed, and the transmittable torque can be flexibly adjusted, even during operation. This results in a wide range of applications, e.g., as starting and powershift elements in dualclutch and automatic transmissions, torque converter lock-up clutches, differential locks, brakes in construction machinery, reversing elements in marine transmissions, or slipping clutches.

Failures of multi-plate clutches must be avoided owing to the often safety-relevant functions, which they have to perform in drive trains. Spontaneous damage is particularly problematic since it can cause the clutch to fail as a result of a single engagement, so it is not detectable in advance. The design of multi-plate 
clutches in the context of spontaneous damage is made more difficult by the different physical and tribological properties of the various friction material types (organic and metallic) as well as different damage characteristics. This paper discusses the load-carrying capacity with respect to spontaneous damage to wet-running multi-plate clutches with paper friction lining. A variety of clutch variants were investigated and then compared with each other.

The damage mechanism of clutches varies according to operating conditions [1] and includes hot spots $[2,3]$, thermoelastic instability [4-6], thermal buckling [7, 8], cracks on the steel plate $[11,12]$, and wear $[9,10]$.

Anderson and Knapp [2] described the characteristics of hot spots in friction systems in automotive applications. Focal hot spots were characterized which were elliptical to circular damage. These focal hot spots were divided into critical and non-critical focal hot spots. Regarding the uncritical focal hot spots, only "cosmetic" interface changes such as discoloration [11] were detected. Plastic deformation of the steel rubbing interfaces occurred at the critical hot spots. These studies were confirmed by later investigations [1218]. Very high interface temperatures [19] occur at the critical hot spots, resulting in microstructural transformations (martensite formation) [1, 16, 19-23]. The martensite formation causes an increase in the volume and local thickening of the steel plates [2, 23, 24]. Owing to the high thermal gradients in the hot spots, high stresses and cracks also arise in the steel plates. $[2,25,26]$. This case of damage is very often described for brake discs $[19,25,27$, 28]. The consequences of hot spots are judder $[16,29-32]$ and the failure of the brake or clutch system $[2,33]$.

The theory of thermoelastic instability (TEI) [4, $34,35]$ has explained the formation of hot spots. Friction heating causes thermal deformation of friction plates, which changes the pressure distribution on friction interfaces. The pressure distribution in turn determines the distribution of the generated frictional heat. These interdependencies create a complex thermo-elastic system, which can become unstable above a certain sliding speed and lead to strong pressure concentrations with very high local temperature and pressure loads. This phenomenon is responsible for many common types of thermal failure of friction elements and is called friction-induced thermoelastic instability (TEI) [36]. However, the theoretical results of TEI are very difficult to verify in practical tests $[23,37,38]$. Practical investigations verify the influence of friction work and friction power on the formation of hot spots [18, 26, 39-41].

A variety of suggestions have been offered in the literature. Given the continuous differences in the thickness of the steel plate, Fieldhouse [22] suggested the use of friction materials with a low Young's modulus so that the unevenness of pressure can be compensated. In addition, a uniform mass distribution is recommended so that the heat distribution is homogeneous [22]. The influence of the Young's modulus on the creation of hot spots has been investigated and proven by several other authors [30, 38, 39, 42-44].

The simulation results by Zagrodzkis [45] have shown that reducing the thickness of the steel disc can significantly improve thermoelastic stability. However, this precaution must be applied with care. Thinner discs are more susceptible to known permanent distortions (coning, warping). In addition, steel discs serve as heat sinks. Reducing their thickness leads to an increase in the mean temperature. References in the literature have also suggested increasing the thermal effusivity [31] and the thermal conductivity $[30,31,46]$ of the friction parts.

This paper presents a comparison method to experimentally examine different variants for their load carrying capacity. The influence of the varied parameters can be investigated and recommendations regarding the load carrying capacity can be formulated.

\section{RESEARCH METHODOLOGY}

The following sections present the materials used (2.1) and test rig (2.2) and the Design of Experiment (2.3). Sections 2.4 and 2.5 explain the basics of Liner Regression. Sections 2.6 to 2.8 present the methods for testing the prerequisites for Linear Regression. Finally, section 2.9 explains the calculation of confidence bands. 


\subsection{Materials}

The experiments were carried out on friction plates with paper lining. The friction linings are supplemented with organic fibers. The friction plates were used as inner plates. For all tests 4 steel plates and 3 lining plates were used (6 friction areas). Fig. 1 shows photographs of the paper lining plates, sized 141/168 mm.

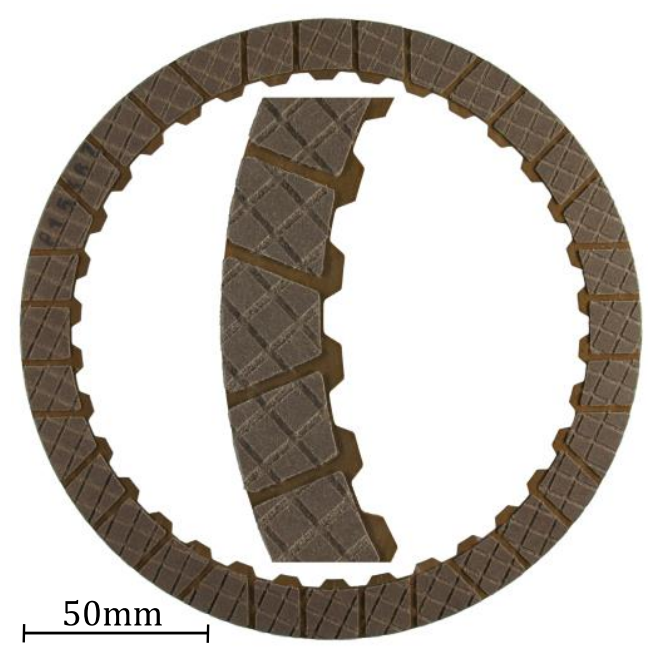

(a)

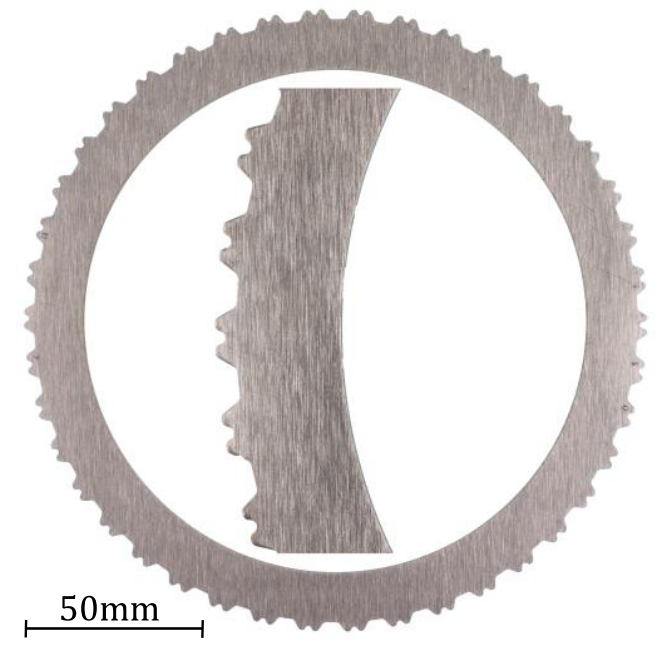

(b)

Fig. 1. (a) Paper lining friction plate; (b) steel plate

Five different variants were examined and compared to a reference system. Each variant represented a modification of one or more of the following parameters: oil flow rate, steel plate thickness, groove pattern (group parallel groove (gpg), wafer groove (wg), group parallel groove combined with wafer groove (gpg+wg)), and the carbon content of the steel plates. The specifications for each system are presented in Table 1 . For variant $C$, the groove was embossed.
In contrast, the groove was milled for the other variants. The varied parameters for each variant are underlined.

Table 1. Specification of the tested variants

\begin{tabular}{|c|c|c|c|c|}
\hline 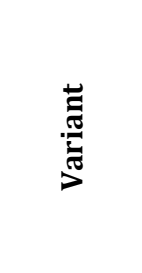 & 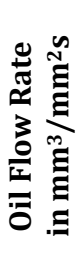 & 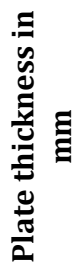 & 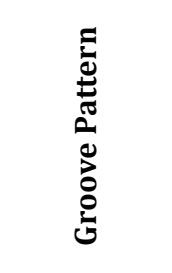 & 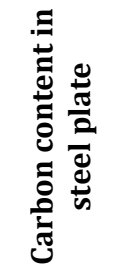 \\
\hline Reference & 0.8 & 1.5 & gpg+wg & Normal \\
\hline A & $\underline{0.4}$ & 1.5 & gpg+wg & Normal \\
\hline B & 0.8 & 1.5 & gpg & Normal \\
\hline $\mathrm{C}$ & 0.8 & 1.5 & $\begin{array}{c}g p g+w g \\
\text { (embossed) }\end{array}$ & Normal \\
\hline D & 0.8 & $\underline{1.85}$ & gpg+wg & Normal \\
\hline E & 0.8 & 1.5 & gpg+wg & $\underline{\text { High }}$ \\
\hline
\end{tabular}

The clutch was supplied centrally with cooling oil from the inside at a defined cooling oil flow. The heating and cooling of the oil and its temperature $\Theta_{\text {oil }}$ were controlled by a thermostat.

\subsection{Experimental setup}

The experiments used to determine the friction work, sliding time, and stress limits of multi-plate clutches were performed on a ZF/FZG KLP-260 component test bench. Fig. 2 illustrates the test bench design.

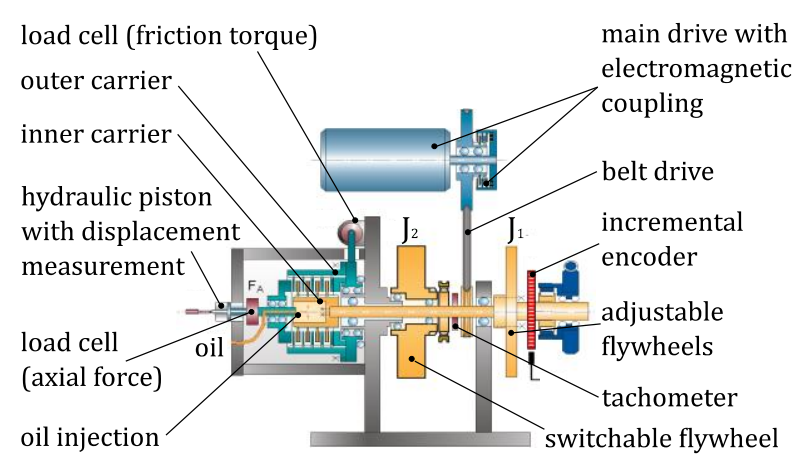

Fig. 2. Sketch of the ZF/FZG KLP-260 test bench according to Meingassner [47]

The outer carrier was fixed to the housing. The inner carrier was fixed to the central shaft, which was also connected to both flywheels (with mass moments of inertia $J_{1}$ and $J_{2}$ ). The friction torque $T_{\mathrm{R}}$ was measured at the outer carrier [42]. 
Before the start of each engagement, the inner carrier was accelerated by the main drive to the differential speed $\Delta n$. Immediately before the engagement, the main drive was separated from the inner carrier by means of an electromagnetic clutch. The maximum and the increase rate of the shifting force $F_{\mathrm{A} \text {,max }}$ were adjustable and were applied by means of a hydraulic piston to the outer plates.

The various parameters $\left.U_{1}, J_{2}, \Delta n, F_{\mathrm{A}, \max }\right)$ offered great flexibility in designing the experiments. Different load levels were easily attainable by varying the differential speed $\Delta \mathrm{n}$ or the axial force $F_{\mathrm{A} \text {,max }}$ without any modification to the equipment. Further load levels were achieved by connecting the mass moments of inertia $J_{1}$ and $J_{2}$. The technical data of the test bench are listed in Table 2.

Table 2. Technical data for the ZF/KLP-260 [47]

\begin{tabular}{|c|c|c|}
\hline Mass moments & $J_{1}=0.1 \ldots 0.75$ & $\mathrm{kgm}^{2}$ \\
\cline { 2 - 3 } of inertia: & $J_{2}=1.0$ & $\mathrm{kgm}^{2}$ \\
\hline $\begin{array}{c}\text { Outside disc } \\
\text { diameter }\end{array}$ & $\mathrm{d}=75 \ldots 260$ & $\mathrm{~mm}$ \\
\hline $\begin{array}{c}\text { Max. friction } \\
\text { torque }\end{array}$ & $T_{\mathrm{R}, \max }=2,000$ & $\mathrm{Nm}$ \\
\hline $\begin{array}{c}\text { Max. differential } \\
\text { speed power } \\
\text { shift mode }\end{array}$ & $\Delta n=0 \ldots 7,000$ & $\mathrm{~min}^{-1}$ \\
\hline Max. axial force & $\mathrm{F}_{\mathrm{A}, \max }=0 \ldots 20$ & $\mathrm{kN}$ \\
\hline Oil temperature & $\Theta_{\mathrm{oil}}=30 \ldots 150$ & ${ }^{\circ} \mathrm{C}$ \\
\hline
\end{tabular}

\subsection{Design of the experiment}

Manufacturing inaccuracies in the components needed to be eliminated before performing the experiment. To compensate inhomogeneities on the clutch plates, the actual step test is preceded by a run-in. Table 3 shows the loads during the run-in. In the case of paper lining, the procedure was divided into three different phases at increasing loads.

Table 3. Load during the run-in

\begin{tabular}{|c|c|c|c|}
\hline Level & Engagements & $\begin{array}{c}\text { Pressure } \\
\text { in } \mathbf{N} / \mathbf{m m}^{2}\end{array}$ & $\begin{array}{c}\text { Friction } \\
\text { work } \\
\text { in } \mathbf{~} / \mathbf{m m}^{2}\end{array}$ \\
\hline 1 & 100 & 0.5 & 0.08 \\
\hline 2 & 200 & 1.0 & 0.12 \\
\hline 3 & 300 & 1.5 & 0.42 \\
\hline
\end{tabular}

The experimental studies were performed as step tests. The fundamental principle of step tests is the stepwise increase of one or more loading parameters as the test progresses [3]. The validity of the step test with regard to the examination of multi-plate clutches has been confirmed by Strebel [42] and Hensel [42, 48].

This study included three varied input parameters: axial force $F_{\mathrm{A} \text {,max }}$, mass moment of inertia $J_{\text {tot }}$ and initial differential speed $\Delta \mathrm{n}$.

The experiments were divided into 4 groups. A step test with 10 levels was performed for each group. The pressure and the moment of inertia were varied among the groups. Within the groups, the initial differential speed was increased at each step. The load levels of the step test for one group are listed in Table 4. The complete experimental design is compiled in Appendix A.

Table 4. Load levels in the step test

\begin{tabular}{|c|c|}
\hline Step & Initial differential speed in RPM \\
\hline 1 & 1800 \\
\hline 2 & 2200 \\
\hline 3 & 2600 \\
\hline 4 & 2900 \\
\hline 5 & 3200 \\
\hline 6 & 3500 \\
\hline 7 & 3800 \\
\hline 8 & 4100 \\
\hline 9 & 4350 \\
\hline 10 & 4600 \\
\hline
\end{tabular}

Each level consisted of ten engagements. The number of engagements was small enough to avoid the occurrence of long-term damage, but big enough to also enable a significant stochastic analysis of any change [42]. The clutch system was disassembled after each step and any changes or damage documented. The time between two successive engagements was 40 seconds. According to Strebel [42], this cycle time is long enough to allow the clutch to re-cool to the oil temperature before the next engagement. The oil injection temperature is sensor-based monitored and controlled to $\Theta_{\text {oil }}=80^{\circ} \mathrm{C}$. This waiting time was important because it guaranteed that the temperature of the clutch was determined only by the current shift and not by the previous engagement. 
In all tests, local thickening of the steel plate (hot spots) marked the end of the step tests. Furthermore, it was observed that the initial damage always consisted of a discoloration of the steel plate, and a local thickening only occurred at a higher mechanical load. The local discolorations occur at lower steel plate temperatures. Local thickening occurs only at higher temperatures $[2,12,14,16]$. Fig. 3 shows the damage that occurred.

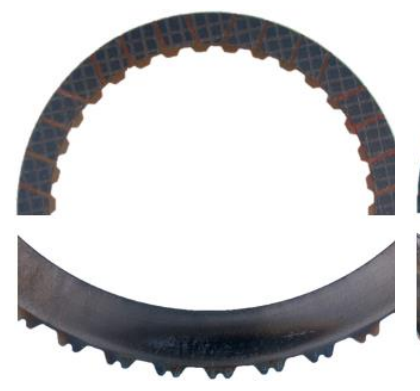

(a)

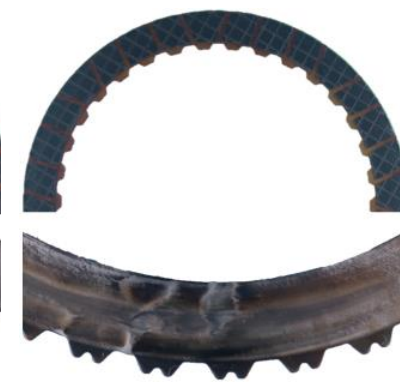

(b)
Fig. 3. (a) Local discoloration; (b) local thickening (hot spots)

\subsection{Linear regression}

Linear regression establishes a mathematical functional description between one or more input variables $x_{\mathrm{i}}$ and an output variable $y$ [49].

$$
y=f\left(x_{1}, \ldots, x_{i}, \ldots, x_{n}\right)
$$

Is it evident from the scatter plot (cf. Fig. 4) that, if the dependence between $n$ input variables and one output variable is linear or approximately linear, according to Schiefer [49] the dependence can be quantitatively described as following:

$$
y=\beta_{0}+\beta_{1} \cdot x_{1}+\cdots+\beta_{n} \cdot x_{n}+e
$$

where $y$ is the output variable, $x_{i}$ is the value of the $\mathrm{i}$-th input variable, $\beta_{i}$ is the coefficients for the i-th variable $x_{i}$ and $e$ is the residual of the mathematical model.

In models with one input variable and one output variable, as in Fig. 4, the linear regression equation is

$$
y=\beta_{0}+\beta_{1} \cdot x+e
$$

where $\beta_{0}$ is the intersection with the $y$-axis, and $\beta_{1}$ the slope of the regression line.
The regression aims to calculate the optimal parameters $\beta_{0}$ and $\beta_{1}$ that approximate the measured values as closely as possible.

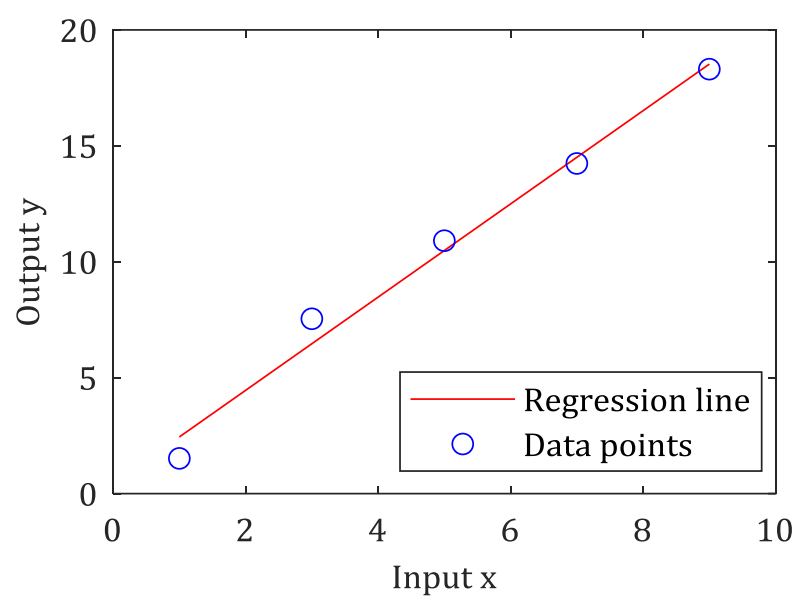

Fig. 4. Dependence of output $y$ on input $x$

According to Ehle [50], in order to ensure the correct estimation of the parameters $\beta_{0}$ and $\beta_{1}$ and enable further analysis of the regression results, some assumptions must be fulfilled regarding the input and output variables and the residuals:

a) Linearity: the relationship between the independent and the dependent variable must be linear.

b) The expected value of the residuals is zero $(\mathrm{E}(\mathrm{e})=0)$.

c) Homoscedasticity: the residuals have constant variance.

d) Independence of error: the residuals do not correlate with each other.

e) Residuals are normally distributed.

\subsection{Ordinary Least Squares Estimation (OLS)}

According to Schiefer [49], the optimal parameters for the regression line are calculated based on the sum of the squares of the distances to the regression line (RSS):

$$
\operatorname{RSS}\left(\beta_{0}, \beta_{1}\right)=\sum_{i=1}^{n}\left(y_{i}-\left(\beta_{0}+\beta_{1} \cdot x_{i}\right)\right)^{2}
$$

The optimal parameters values of $\beta_{0}$ and $\beta_{1}$ for which the RSS is minimized are the OLS estimators and are given by: 


$$
\hat{\beta}=\arg \min _{\beta_{0}, \beta_{1}} \sum_{i=1}^{n}\left(y_{i}-\left(\beta_{0}+\beta_{1} \cdot x_{i}\right)\right)^{2}
$$

with

$$
\hat{\beta}=\left(\begin{array}{c}
\beta_{0, o p t} \\
\beta_{1, o p t}
\end{array}\right)
$$

where $\beta_{0, o p t}$ and $\beta_{1, \text { opt }}$ are the optimal parameters. According to Karpfinger [51], the optimal parameters can be estimated by solving the following linear system of equations if the data points $x_{1}, \ldots, x_{M}$ and $y_{1}, \ldots, y_{M}$, are given:

$$
A^{T} A \cdot \hat{\beta}=A^{T} b
$$

with

$$
b=\left(\begin{array}{c}
y_{1} \\
\vdots \\
y_{M}
\end{array}\right) \text { and } A=\left(\begin{array}{cc}
1 & x_{1} \\
\vdots & \vdots \\
1 & x_{M}
\end{array}\right)
$$

The solution of equation 5 states [51]:

$$
\hat{\beta}=\left(A^{T} A\right)^{-1} A^{T} b
$$

\subsection{Homoscedasticity}

In statistics, homoscedasticity refers to the fact that the variance of the residuals is constant over all measurements. According to Olive [52], this property can be verified graphically by assessing the residual plot: If the dispersion of the residuals is constant over the whole range of values, homoscedasticity is given (Fig. 5 (a)). In the case that the variance fluctuates, the data is heteroscedastic (Fig. 5 (b)).

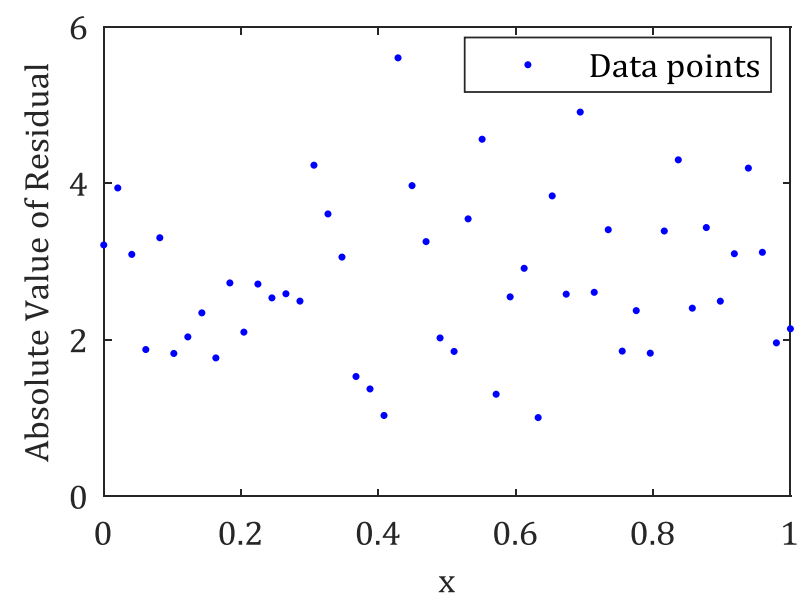

(a)

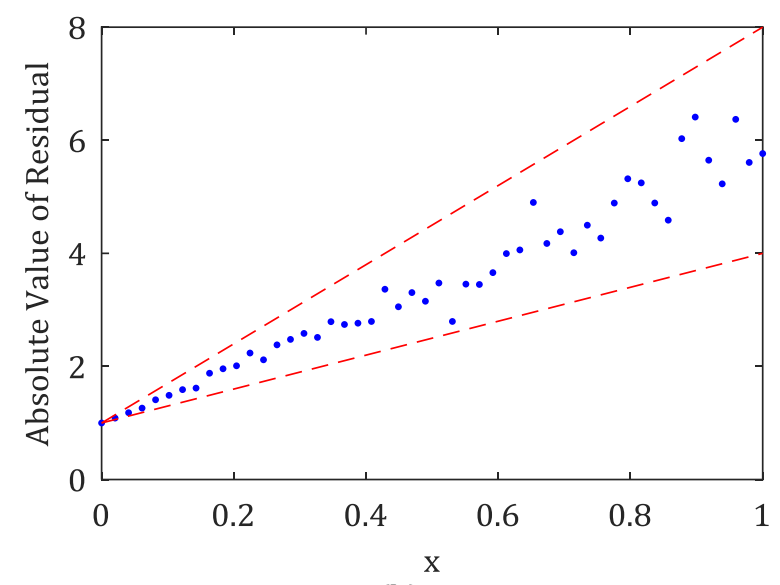

(b)

Fig. 5. (a) Example plot of homoscedasticity; (b) Example plot of heteroscedasticity.

\subsection{Durbin-Watson test}

The Durbin-Watson test is a statistical test used to examine the presence of first-order correlation and is described by Dreger [53] and Hedderich [54]. First-order autocorrelation is the correlation between two subsequent residual values:

$$
e_{i}=\rho \cdot e_{i-1}+\tau_{i}
$$

where $e_{i}$ is the residual for the i-th measurement, $\rho$ is the coefficient of correlation, and $\tau_{i}$ is a disturbance variable.

The test statistic $d$ is given by:

$$
d=\frac{\sum_{i=2}^{M}\left(e_{i}-e_{i-1}\right)^{2}}{\sum_{i=1}^{M}\left(e_{i}\right)^{2}} \approx 2(1-\rho)
$$

where $M$ is the number of measurements.

There is no first-order autocorrelation if $\rho=0$ or, alternatively, $d=2$.

\subsection{Kolmogorov-Smirnov test}

The Kolmogorov-Smirnov test $[52,55]$ is a nonparametric statistical test which enables the comparison of two probability distributions. An empirical distribution function $F(x)$ is compared to theoretical distribution function $F_{0}(x)$ defined by the null hypothesis $H_{0}$ [51]:

$$
\begin{aligned}
& H_{0}: F(x)=F_{0}(x) \\
& H_{1}: F(x) \neq F_{0}(x)
\end{aligned}
$$


The data must be sorted in ascending order $x_{1} \leq$ $x_{2} \leq \ldots \leq x_{n}$. Using the sorted data, the empirical distribution function is calculated and compared to the theoretical distribution function for each data point. The Kolmogorov-Smirnov statistic is given by the following expression [55]:

$$
D=\sup \left|F(x)-F_{0}(x)\right|
$$

The test statistic is then compared to a tabulated critical value of the Kolmogorov distribution for a particular statistical significance $\alpha$. If the test statistic is larger than the critical value, the null hypothesis can be rejected. Table 5 shows an extract of the critical values for the test statistic for the Kolmogorov-Smirnov test.

Table 5. Extracts from the Kolmogorov distribution table from Lilliefors [55]

\begin{tabular}{|l|c|c|c|}
\hline $\mathbf{n}$ & $\boldsymbol{\alpha}=\mathbf{0 . 1}$ & $\boldsymbol{\alpha}=\mathbf{0 . 0 5}$ & $\boldsymbol{\alpha}=\mathbf{0 . 0 1}$ \\
\hline 10 & 0.239 & 0.258 & 0.294 \\
\hline 15 & 0.201 & 0.220 & 0.257 \\
\hline 20 & 0.174 & 0.190 & 0.231 \\
\hline
\end{tabular}

\subsection{Confidence bands of the mean}

After the regression has been performed, it is possible to calculate the confidence interval for the regression parameters $\beta_{0}$ and $\beta_{1}$. However, the confidence interval for the regression coefficient alone has little practical significance with regard to the meaningfulness of differences between two regression lines [50]. The aim is to determine statistically significant differences in the mean load-carrying capacity between two variants while taking into account the uncertainties of the regression line.

According to Ehle [50] and Olive [52], the confidence band specifies an interval in which the expected value of the output $y$ for an input $x$ is within it with a significance level $\alpha$. The confidence band is different from the prediction interval. The prediction deals with the prediction of future values, while the confidence band is a range for the expected value for the dependent variable. The width of the interval is larger because of the uncertainty of the regression coefficients and the normal uncertainty of a measurement. Only the confidence bands are used in the following analysis of the regression lines. Fig. 6 shows the confidence band for the expected value of the output for the given data points.

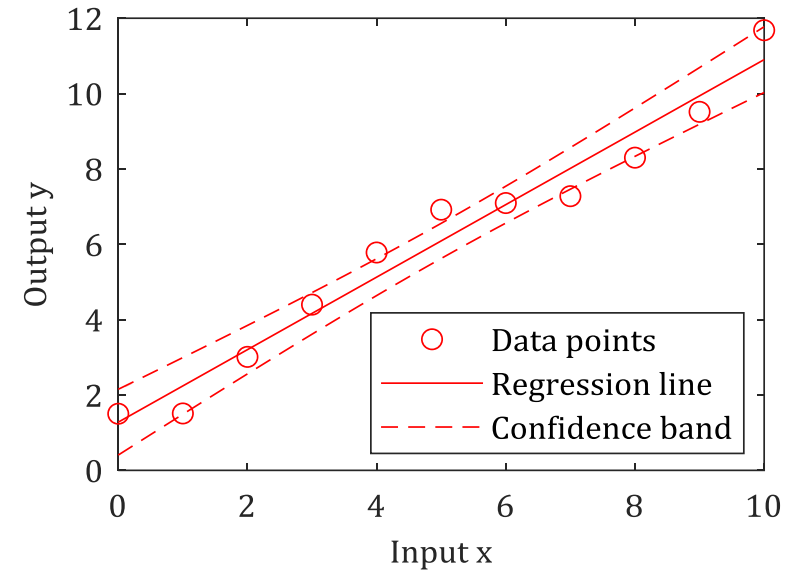

Fig. 6. Confidence band for a regression line

The confidence interval is given by:

with

$$
C I=\left[I_{1} ; I_{2}\right]
$$

$$
\begin{aligned}
& I_{1}=\hat{y}(x)-t_{1-\alpha / 2, n-2} \cdot S E(\hat{y}(x)) \\
& I_{2}=\hat{y}(x)+t_{1-\alpha / 2, n-2} \cdot S E(\hat{y}(x))
\end{aligned}
$$

and the standard error for the expected value

$$
S E(\hat{y}(x))=s_{\text {res }} \sqrt{\frac{1}{n}+\frac{(x-\bar{x})^{2}}{s_{x}^{2}(n-1)}}
$$

in which $t_{1-\alpha / 2, n-2}$ is the student-t distribution with $n-2$ degrees of freedom and significance level $\alpha ; \hat{y}(x)$ is the expected value for a given input $x ; s_{x}$ is the empirical standard deviation for the input $x$; and $n$ is the number of data points. The equations were extracted from Ehle [50].

\section{RESULTS AND DISCUSSION}

The linear regression was performed for one reference system as well as the five variants $A, B$, C, D, and E (cf. 0 Materials). In this analysis, the test data from each step test for the initial damage (local discoloration) and the last load stage before failure (local thickening) were used and presented in a diagram (friction work over friction power). Each data point is the average of 10 engagements for the respective load stage. The detailed evaluation methodology can looked up in Schneider [18]. The engagements in which failure of the clutch system occurs were not used because the measured data showed a high degree of inaccuracies in the event of failure. 
The results of the linear regression are presented in section 3.1. Sections 3.2 to 3.6 further deepen the analysis of each variant and compare each variant with the reference.

\subsection{Linear regression}

Table 6 shows the results of the linear regressions for the reference system as well as the five variants $\mathrm{A}, \mathrm{B}, \mathrm{C}, \mathrm{D}$, and $\mathrm{E}$ using the sliding time $t_{s}$ as independent input and the friction loss $q_{s}$ as dependent output, as in the following equation [56]:

$$
q_{s}=\gamma \cdot t_{s}+q_{s, 0}
$$

The linearity of the relationship between slip time and friction work has been proven by Strebel [3].

Table 6. Results of linear regression

\begin{tabular}{|c|c|c|c|c|}
\hline \multirow{2}{*}{ System } & \multicolumn{2}{|c|}{ First damage } & \multicolumn{2}{c|}{ Prior to failure } \\
\cline { 2 - 5 } & $\boldsymbol{\gamma}$ & $\boldsymbol{q}_{\boldsymbol{s}, \mathbf{0}}$ & $\boldsymbol{\gamma}$ & $\boldsymbol{q}_{\boldsymbol{s}, \mathbf{0}}$ \\
\hline Reference & 0.147 & 1.159 & 0.282 & 1.563 \\
\hline Variant A & 0.256 & 0.873 & 0.398 & 1.485 \\
\hline Variant B & 0.215 & 1.098 & 0.280 & 1.504 \\
\hline Variant C & 0.211 & 1.098 & 0.310 & 1.495 \\
\hline Variant D & 0.244 & 1.085 & 0.422 & 1.085 \\
\hline Variant E & 0.326 & 0.994 & 0.547 & 1.167 \\
\hline
\end{tabular}

The following paragraphs check all of the requirements and assumptions from section 2.4.

Table 7 shows the expected value of the residuals. The assumption that the expected value of the residuals equals zero can be justified in both cases.

Table 7. Expected value of the residuals

\begin{tabular}{|c|c|}
\hline Load level & E[e] \\
\hline First damage & $5.5 \cdot 10^{-17}$ \\
\hline Prior to failure & $-9.25 \cdot 10^{-17}$ \\
\hline
\end{tabular}

The homoscedasticity can be checked using Fig. 7. The variance of the residuals over the friction work showed no particular tendencies, and the variance can be assumed to be constant.

The test statistics of the Durbin-Watson Tests was equal to $D W=2.70$ for the first damage measurements and $D W=2.92$ for the measurements prior to damage. The hypothesis of first-order autocorrelation were rejected at the $5 \%$ significance level for both cases.

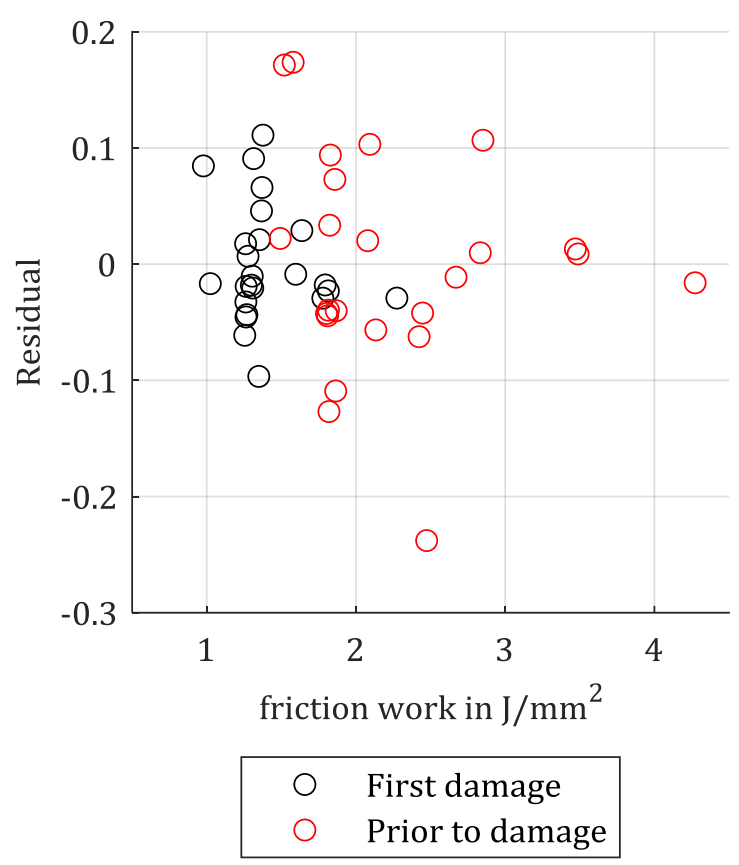

Fig. 7. Friction work $q_{s}$ vs. residuals $e_{i}$

The residuals were normalized so that the values ranged between -1 and 1 then assessed for standard normal distribution using the Kolmogorov-Smirnov test:

$$
\begin{aligned}
& H_{0}: F(x)=\mathcal{N}(0,1) \\
& H_{1}: F(x) \neq \mathcal{N}(0,1)
\end{aligned}
$$

The results of the Kolmogorov-Smirnov test for normality of the residuals for $n=24$ and $\alpha=$ 0.05 are presented in Table 8. Since the test statistics were smaller than the critical value in both cases, the null hypothesis $H_{0}$ could not be rejected. The normalized residuals were standard normally distributed.

Table 8. Results of Kolmogorov-Smirnov test

\begin{tabular}{|c|c|c|c|}
\hline Load level & D & $\boldsymbol{D}_{\text {crit,0.05 }}$ & $\boldsymbol{H}_{\mathbf{0}}$ \\
\hline First damage & 0.194 & 0.269 & not rejected \\
\hline Prior to failure & 0.126 & 0.269 & not rejected \\
\hline
\end{tabular}

\subsection{Reference}

Fig. 8 shows the plot of the data points, the regression line and the $90 \%$ confidence band for the reference system. Fig. 8 (a) shows the data points from the initial damage and Fig. 8 (b) from load level before to failure. 

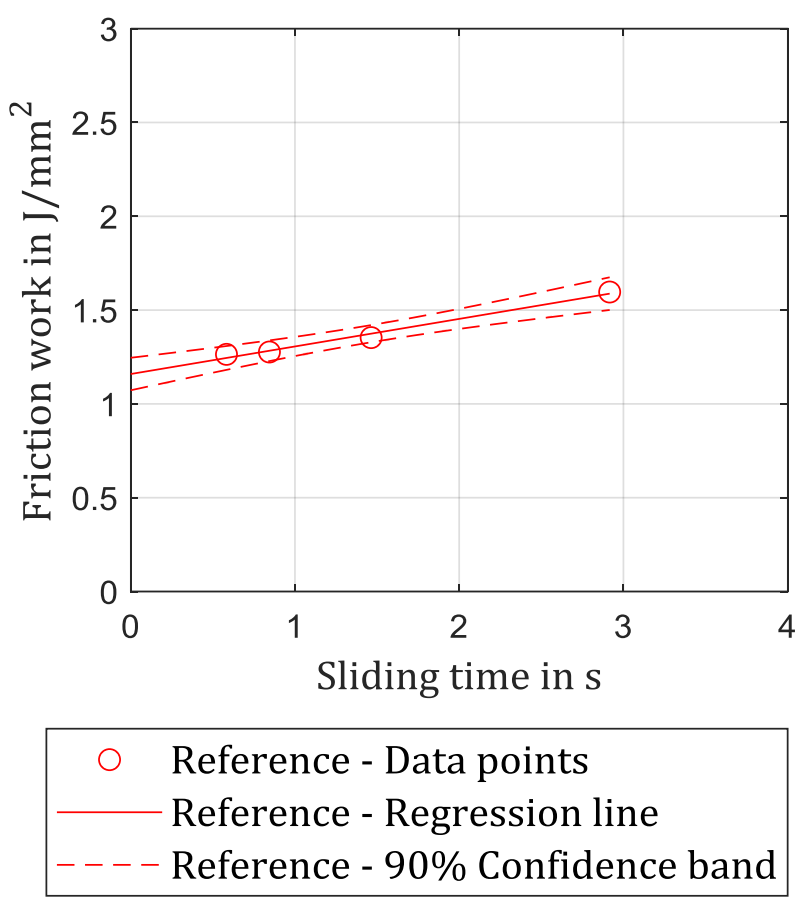

(a)

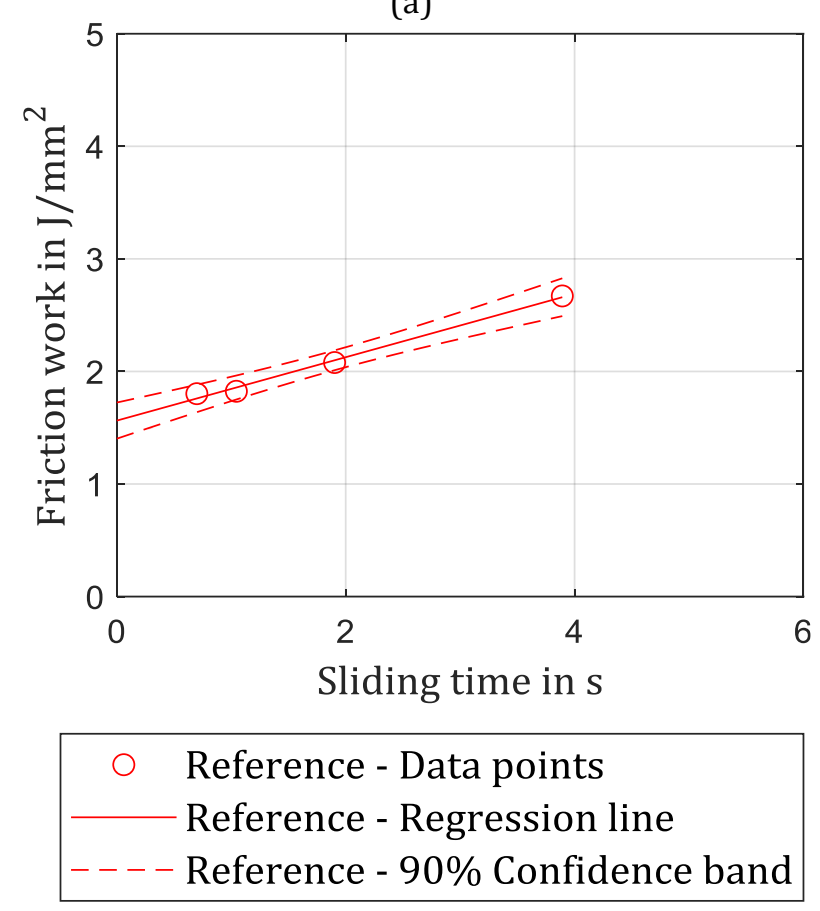

(b)

Fig. 8. Reference - (a) First damage - local discoloration; (b) Load level prior to failure

\subsection{Variant A - lower oil flow}

The comparison of the load carrying capacity for the reference and variant A is shown in Fig. 9. The test conditions for variant A were the same as for the reference, but at a lower oil flow $\left(0.4 \mathrm{~mm}^{3} / \mathrm{mm}^{2} \mathrm{~s}\right.$ instead of $\left.0.8 \mathrm{~mm}^{3} / \mathrm{mm}^{2} \mathrm{~s}\right)$.
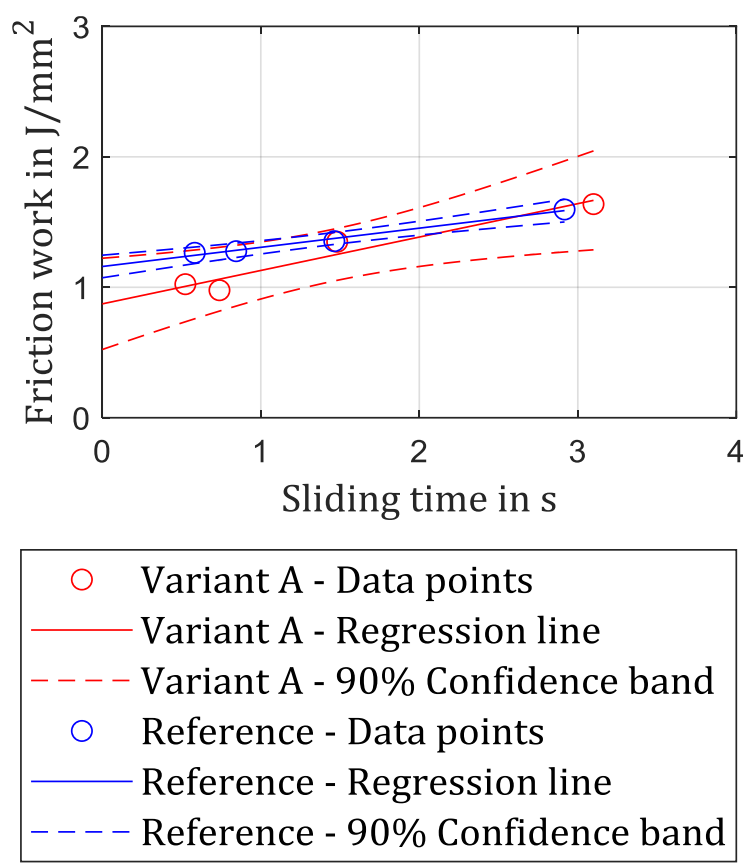

(a)

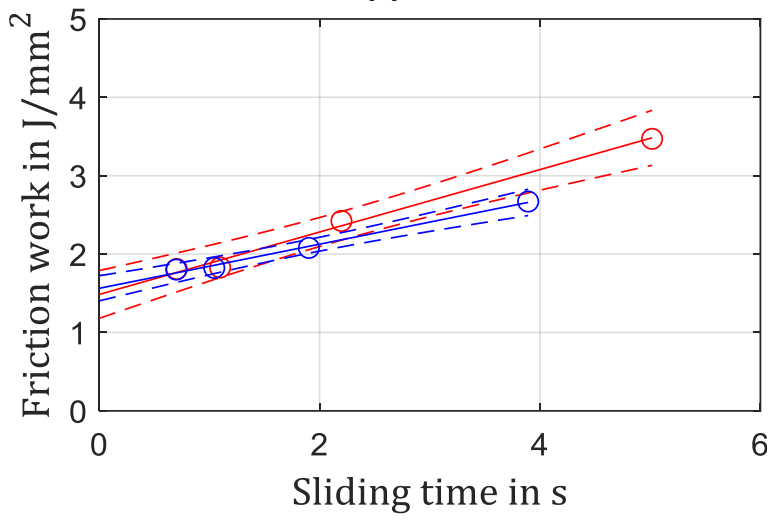

\begin{tabular}{|cc|}
\hline$\circ$ & Variant A - Data points \\
\hline--- & Variant A - Regression line \\
& Variant A - 90\% Confidence band \\
& Reference - Data points \\
\hline--- & Reference - Regression line \\
- & Reference - 90\% Confidence band
\end{tabular}

(b)

Fig. 9. Variant A - (a) First damage - local discoloration; (b) load level prior to failure

In the case of initial damage (Fig. 9 (a)), the regression line of variant $A$ was steeper than the regression line for the reference. The slope of the regression line for variant $\mathrm{A}$ was almost two times greater compared to the reference, but had a smaller intercept value $q_{s, 0}$. Based on the confidence bands, no statement could be made about significant differences in the load carrying capacity, since both confidence bands overlapped for all sliding times. 
In the case prior to failure (Fig. 9 (b)), the regression line of variant $A$ was also steeper than the regression line for the reference, but both regression lines had a similar intercept value. Although it seems that the load carrying capacity of variant A had the tendency to increase faster than the reference, no significant statement can be made owing to the overlapping of the confidence bands.

\subsection{Variant B - group parallel groove}

The comparison of the load carrying capacity for the reference and variant B is shown in Fig. 10. The test conditions for variant B were the same as for the reference, but with group parallel grooves instead of a group parallel groove combined with wafer grooves.

In the case of initial damage (Fig. 10 (a)), the regression line for the load carrying capacity for variant B was slightly steeper than the regression line for the reference. Both regression lines had similar values for the intercept $q_{s, 0}$.

Since no range existed in the measured data where the confidence intervals did not intersect, it was not possible to make statements about differences in the load carrying capacity of these two clutch systems regarding the load level of first damage.

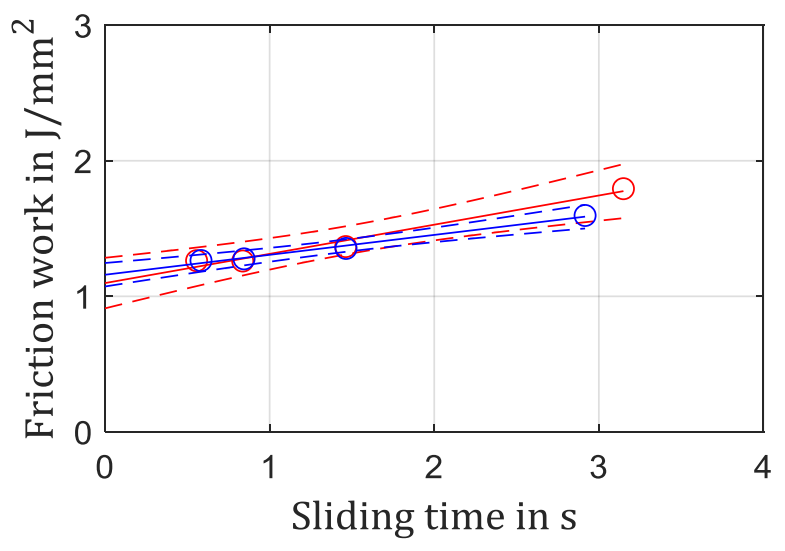

\begin{tabular}{|c|}
\hline$\circ \quad$ Variant B - Data points \\
\hline---- Variant B - Regression line \\
O Reference - Data points \\
\hline - Reference - Regression line \\
---- Reference - $90 \%$ Confidence band
\end{tabular}

(a)
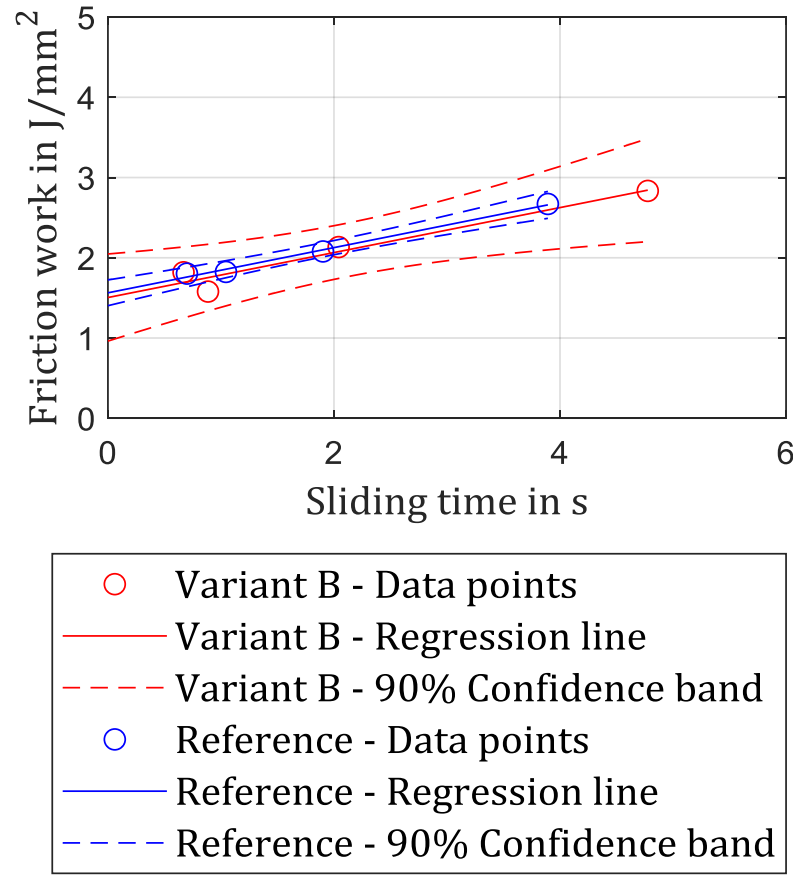

(b)

Fig. 10. Variant B - (a) First damage - local discoloration; (b) load level prior to failure

The regression lines for the engagements prior to failure (Fig. 10 (b)) had similar tendencies. There was no considerable difference between the slopes (less than 1\%) and the intercept value (less than 4\%) of both regression lines.

The spreading of the measurements for variant $B$ around the regression line resulted in a broad confidence band for variant $B$, which enclosed the entire confidence band for the reference. No significant statement regarding differences in load carrying capacity could be made.

\subsection{Variant $\mathrm{C}$ - embossed groove}

The comparison of the load carrying capacity for the reference and variant $C$ is shown in Fig. 11. The test conditions for variant $\mathrm{C}$ were the same as for the reference, but with an embossed instead of milled grooves.

Regarding initial damage (Fig. 11 (a)), the regression line for the load carrying capacity for variant $C$ was steeper than the reference. Variant $C$ had a slightly smaller intercept value $q_{s, 0}$ and bigger slope $\gamma$. However, these differences between the regression lines did not result in a significant difference between the expected values for the reference and the variant considered. 

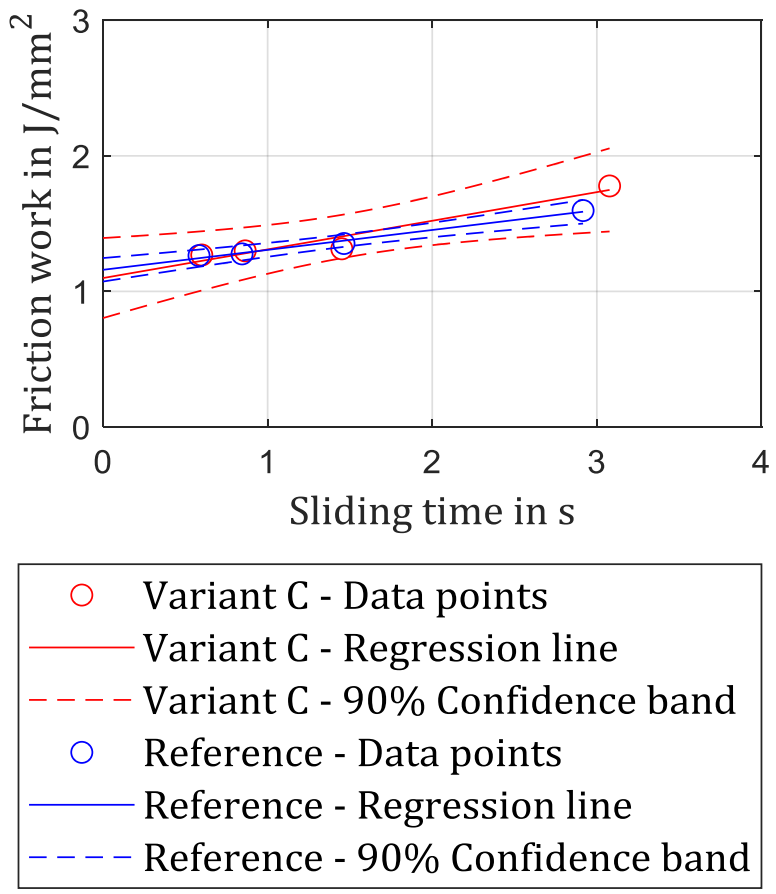

(a)
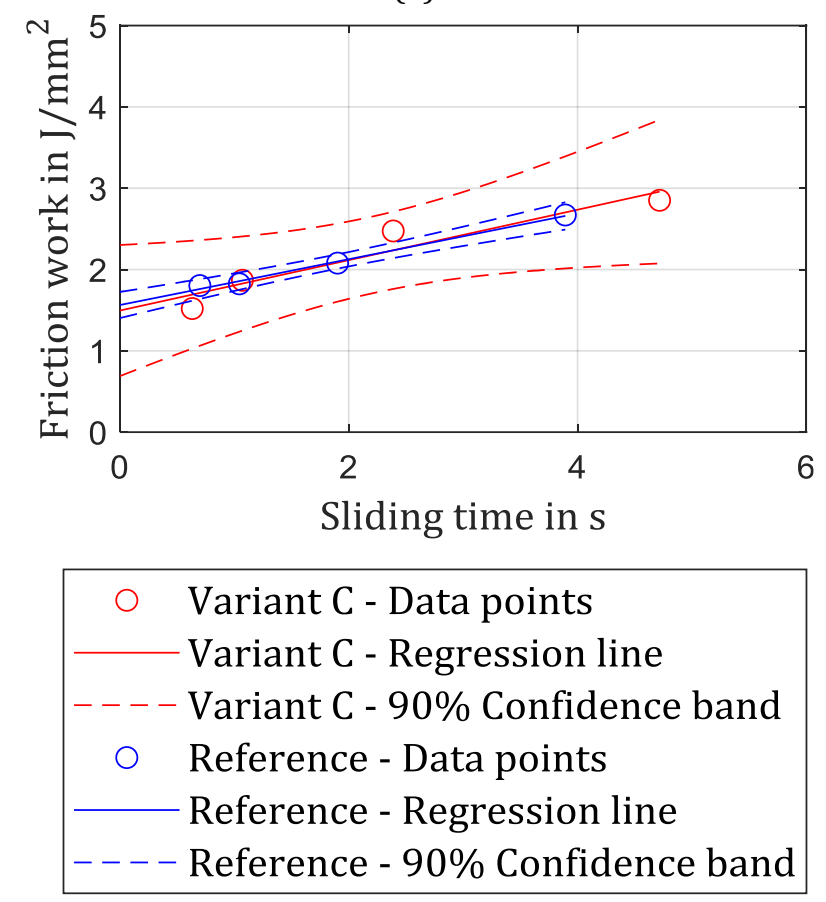

(b)

Fig. 11. Variant $\mathrm{C}-$ (a) First damage - local discoloration; (b) load level prior to failure

In the case prior to failure (Fig. 11 (b)), both regression lines showed almost identical behavior. The differences between the regression coefficients were minor. The confidence band of the variant fully included the reference confidence band, resulting in no significant statement regarding the difference in load carrying capacity.

\subsection{Variant $D$ - thicker steel plate}

Variant D had an increased plate thickness of 1.85 $\mathrm{mm}$ compared to $1.5 \mathrm{~mm}$ for the reference system. The comparison of the load carrying capacity for the reference and variant $\mathrm{D}$ is shown in Fig. 12.

In the case of initial damage (Fig. 12 (a)), the regression line of variant $\mathrm{D}$ was steeper than the regression line for the reference. The slope of the regression line for variant $\mathrm{D}$ was $65 \%$ steeper than the reference slope but had a smaller intercept value $q_{s, 0}$.

In the case prior to failure (Fig. 12 (b)), the regression line of variant $\mathrm{D}$ was also steeper than the regression line for the reference, but both regression lines had a similar intercept value. Based on the confidence bands, it can be stated that the load carrying capacity of variant D was statistically significantly higher from a sliding time of about 2.3 seconds onward. Between $0 \mathrm{sec}$ and $2.3 \mathrm{sec}$, no significant statement can be made since the confidence bands for both systems overlapped. From a slip time of 2.3 seconds onward, the confidence bands no longer overlapped, so a statement can be made about a significant difference in the load carrying capacity of the systems. Regarding long sliding times, the load carrying capacity of variant D was significantly higher than the reference.
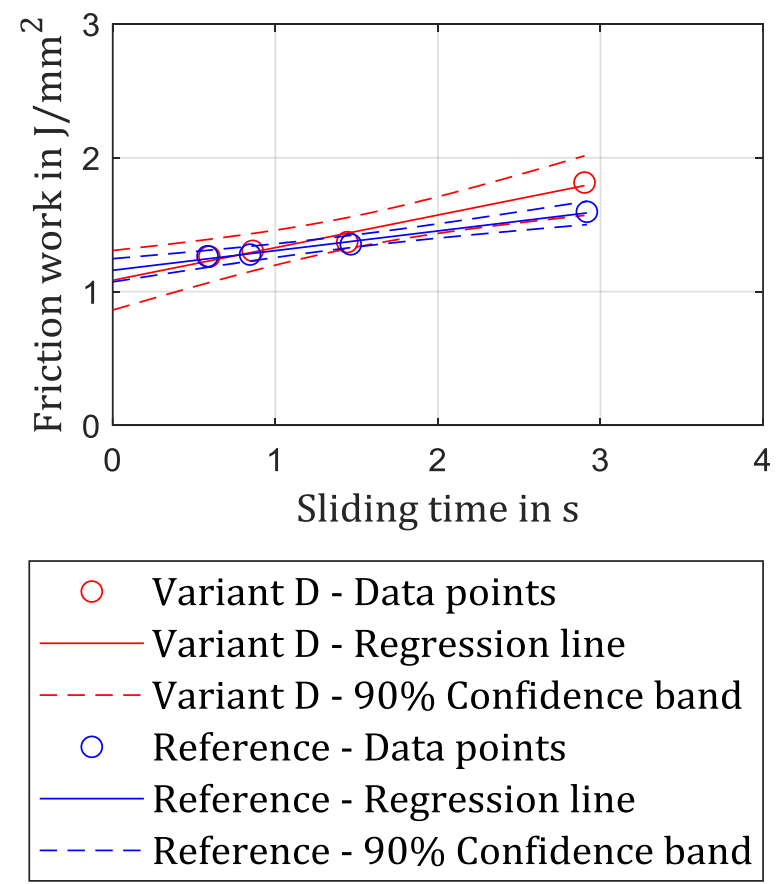

(a) 

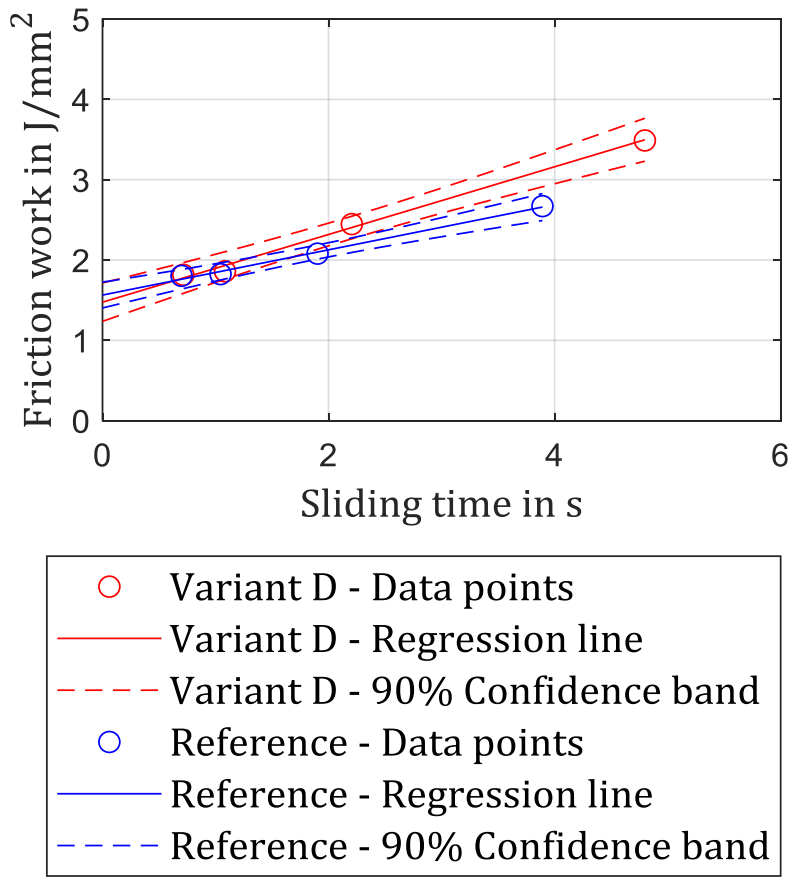

(b)

Fig. 12. Variant D - (a) First damage - local discoloration; (b) load level prior to failure

\subsection{Variant E - higher carbon content}

Variant E had an elevated carbon content in the steel plate. The comparison of the load carrying capacity for the reference and variant $\mathrm{E}$ is shown in Fig. 13.

In the case of initial damage (Fig. 13 (a)), the regression line of variant $\mathrm{E}$ was steeper than the regression line for the reference.

Theoretically, the load capacity of the variant was greater than that of the reference for longer sliding times. However, this difference could not be statistically determined considering the given confidence bands for the expected value for the slip work $q_{s}$. Both confidence intervals still slightly overlapped. An extrapolation of the regression lines would emphasize the difference even more but this would also enlarge the confidence bands.

In the case prior to failure (Fig. 13 (b)), the regression line of variant $\mathrm{E}$ was twice as steep as the regression line for the reference and had a smaller value for the intercept. For long sliding times from 2.8 sec onward, the load carrying capacity of variant $E$ was significantly higher than the reference, since the confidence bands no longer overlapped.
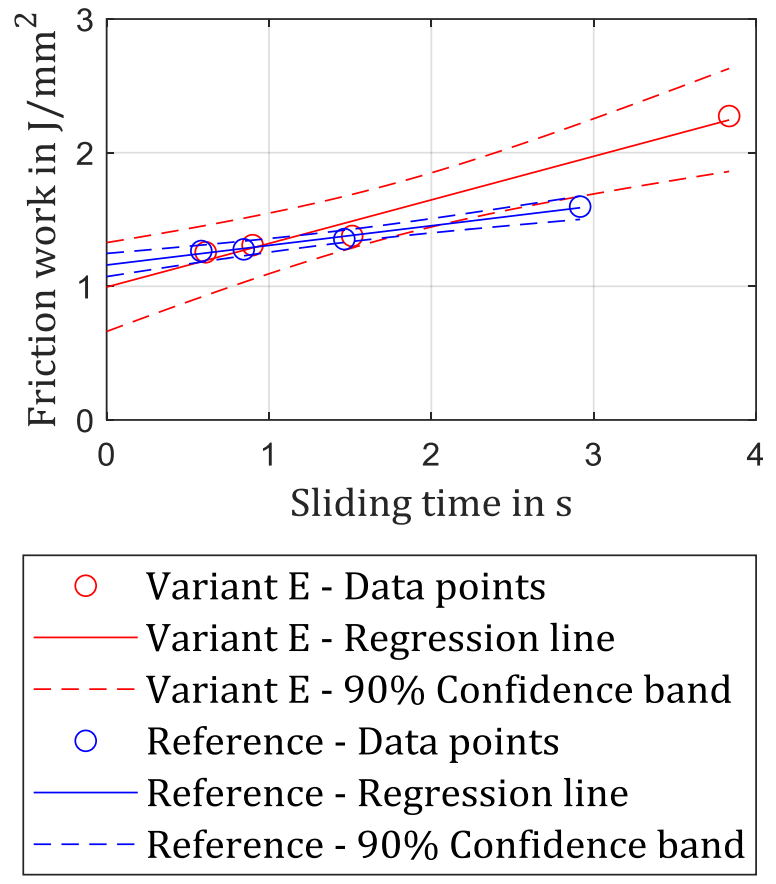

(a)
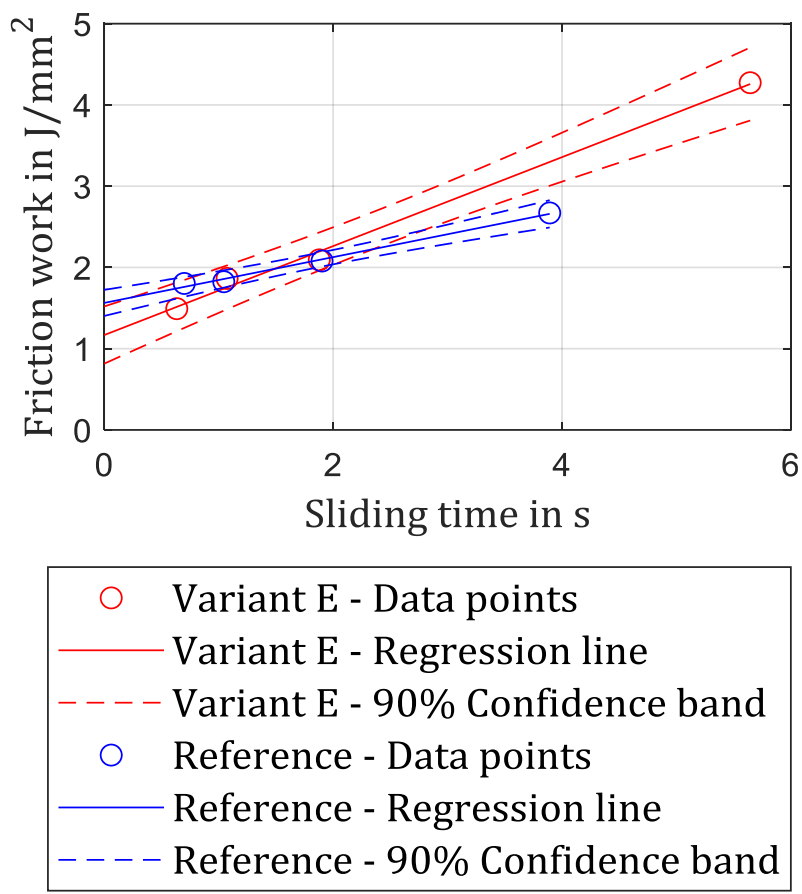

(b)

Fig. 13. Variant E - (a) First damage - local discoloration; (b) load level prior to failure

\section{CONCLUSION}

This paper examined the influence of oil flow rate, plate thickness, carbon content and different groove patterns on the load carrying capacity of wet-running multi-plate clutches. 
After a run-in used to eliminate manufacturing inaccuracies, the clutch system was subjected to a step test in which the load applied to the clutch was increased after each step. The first load levels in which damage of the clutch plate was visible and the level prior to failure were recorded for further analysis of the load carrying capacity.

The formulated method for comparing multiplate clutches takes into account the variance of the measurements in order to consider significant differences, which is not possible by simply comparing two regression lines.

A linear regression was run on the measurements for the reference system and variants $A, B, C, D$, and $E$ in order to quantify the relationship between sliding time and friction work and to determine the maximal load carrying capacities. The $90 \%$ confidence band was computed for each system. The measurements, the regression line, and the confidence band of the variants were plotted and compared to the reference.

In order to enable statistically significant statements about differences in load capacity, the confidence bands were compared and possible overlaps analyzed. Significant statements can be made for ranges in which the confidence bands did not overlap.

Although some tendencies and trends were identifiable with respect to the influence of various parameters on the load carrying capacity in comparison to the reference system, only two datasets permitted the formulation of a statement with respect to the differences in the mean of the load capacity.

The variation of the oil flow rate influenced the loads at which the first damages occurred. For small sliding times, the load carrying capacity of variant A was smaller than that of the reference. For long sliding times, the load carrying capacity of variant A was higher than the reference.

Variations in oil flow (A) and groove patterns $(B, C)$ did not have any significant effect on load capacities. Variations of plate thickness (D) and carbon content (E) did have a significant effect on the load capacity regarding the failure level.

\section{Acknowledgement}

The presented results were based on research project FVA no. 515/V, which was self-financed by the Research Association for Drive Technology e.V. (FVA). The authors are thankful for the sponsorship and support received from the FVA and the members of the project committee.

\section{REFERENCES}

[1] R.B. Dinwiddie, K. Lee, IR-camera methods for automotive brake system studies, Proceedings of the SPIE, Thermosense XX, vol. 3361, pp. 66-74, 1998, doi: $10.1117 / 12.304744$

[2] A.E. Anderson, R.A. Knapp, Hot spotting in automotive friction systems, Wear 135, iss. 2, pp. 319-337, 1990, doi: 10.1016/00431648(90)90034-8

[3] J.Y. Jang, M.M. Khonsari, On the Formation of Hot Spots in Wet Clutch Systems, Journal of Tribology, vol. 124, iss. 2, pp. 336-345, 2002, doi: $10.1115 / 1.1402132$

[4] J.R. Barber, Thermoelastic Instabilities in the Sliding of Comforming Solids, Proceedings of the Royal Society A: Mathematical, Physical and Engineering Sciences, vol. 312, pp.381-394, 1969, doi: 10.1098/rspa.1969.0165

[5] Y.-B. Yi, S. Du, J.R. Barber, J.W. Fash, Effect of Geometry on Thermoelastic Instability in Disk Brakes and Clutches, Journal of Tribology, vol. 121 , iss. 4, pp. 661-666, 1999, doi: $10.1115 / 1.2834120$

[6] J. Zhao, Y.-B. Yi, H. Li, Effects of frictional material properties on thermoelastic instability deformation modes, Proceedings of the Institution of Mechanical Engineers, Part J: Journal of Engineering Tribology, vol. 229, iss. 10, pp.1239-1246, 2015, doi: $10.1177 / 1350650115576783$

[7] X. Cenbo, M. Biao, L. Heyan, Z. Fenglian, W. Da, Experimental Study and Thermal Analysis on the Buckling of Friction Components in Multi-Disc Clutch, Journal of Thermal Stresses, vol. 38, iss. 11, pp. 1323-1343, 2015, doi: 10.1080/01495739.2015.1073524

[8] Z. Chen, Y.-B. Yi, J. Zhao, Fourier finite element model for prediction of thermal buckling in disc clutches and brakes, Journal of Thermal Stresses, vol. 39, iss. 10, pp. 1241-1251, 2016, doi:10.1080/01495739.2016.1215728 
[9] H.-R. Cho, Y. Je, K.-H. Chung, Assessment of Wear Characteristics of Paper-Based Wet Friction Materials, International Journal of Precision Engineering and Manufacturing, vol. 19, pp. 705711, 2018, doi: 10.1007/s12541-018-0084-1

[10] A.P. Ompusunggu, P. Sas, H. van Brussel, Distinguishing the effects of adhesive wear and thermal degradation on the tribological characteristics of paper-based friction materials under dry environment: A theoretical study, Tribology International, vol. 84, pp. 9-21, 2015, doi: 10.1016/j.triboint.2014.11.016

[11] D. Bryant, J.D. Fieldhouse, C.J. Talbot, Brake Judder - An Investigation of the Thermo-elastic and Thermo-plastic Effects during Braking, International Journal of Vehicle Structures \& Systems, vol. 3, no. 1, pp. 57-72, 2011, doi: 10.4273/ijvss.3.1.07

[12] D. Fairbank, K. Maruo, S. Du, T. Newcomb, ATF Additive Effects on Hot Spot Formation in Wet Clutches, In: SAE Technical Paper Series, SAE International 400 Commonwealth Drive, Warrendale, PA, United States, 2001, doi: 10.4271/2001-01-3594

[13] B. Hämmerl, Lifetime and Temperature Behavior of Oil-Cooled Multi-plate Clutches under Load Collective Stresses, PhD thesis, Technical University Munich, Munich, 1995. (in German)

[14] M. Hensel, H. Pflaum, K. Stahl, FVA No. 515 II Issue 1089 - Service life of multi-plate clutches Final report: Influences of new friction linings and oils as well as the operating mode on the lifetime of multi-plate clutches, Forschungsvereinigung Antriebstechnik e.V., Frankfurt/Main, 2014. (in German)

[15] T. Hirano, K. Maruo, X. Gu, T. Fujii, Development of Friction Material and Quantitative Analysis for Hot Spot Phenomenon in Wet Clutch System, In: SAE Technical Paper Series, SAE International 400 Commonwealth Drive, Warrendale, PA, United States, 2007, doi: 10.4271/2007-01-0242

[16] H. Kasem, J.F. Brunel, P. Dufrénoy, M. Siroux, B. Desmet, Thermal levels and subsurface damage induced by the occurrence of hot spots during highenergy braking, Wear, vol. 270, iss. 5-6, pp.355364, 2011, doi: 10.1016/j.wear.2010.11.007

[17] F. Pfleger, Shifting and lifetime behavior of multiplate clutches, PhD thesis, Technical University Munich, Munich, 1998. (in German)

[18] T. Schneider, M. Strebel, H. Pflaum, K. Stahl, Spontaneous damage to wet-running multi-plate clutches with organic and metallic friction linings, Forschung im Ingenieurwesen / Engineering Research, vol. 83, pp. 199-207, 2019, doi: 10.1007/s10010-019-00304-1
[19] M.C. Fec, H. Sehitoglu, Thermal-mechanical damage in railroad wheels due to hot spotting, Wear, vol. 102, iss. 1-2, pp. 31-42, 1985, doi: 10.1016/0043-1648(85)90089-4

[20] G. Antoni, T. Désoyer, F. Lebon, A combined thermo-mechanical model for Tribological Surface Transformations, Mechanics of Materials, vol. 49, pp.92-99, 2012, doi: 10.1016/j.mechmat.2011.12.005

[21] G. Degallaix, P. Dufrénoy, J. Wong, P. Wicker, F. Bumbieler, Failure Mechanisms of TGV Brake Discs, Key Engineering Materials, vol. 345-346, pp.697-700, 2007, doi: 10.4028/www.scientific.net/KEM.345-346.697

[22] J.D. Fieldhouse, D. Bryant, C.J. Talbot, Hot Judder An Investigation of the Thermo-Elastic and Thermo-Plastic Effects during Braking, SAE International Journal of Passenger Cars Mechanical Systems, vol. 4, iss. 2, pp. 1086-1101, 2011, doi: 10.4271/2011-01-1575

[23] K. Lee, F.W. Brooks, Hot Spotting and Judder Phenomena in Aluminum Drum Brakes, Journal of Tribology, vol. 125 , iss. 1 , pp. 44-51, 2003, doi: 10.1115/1.1506315

[24] T.K. Kao, J.W. Richmond, A. Douarre, Brake disc hot spotting and thermal judder: an experimental and finite element study, International Journal of Vehicle Design, vol. 23, no. 3-4, pp. 276-296, 2000, doi: 10.1504/ijvd.2000.001896

[25] P. Dufrénoy, G. Bodovillé, G. Degallaix, Damage mechanisms and thermomechanical loading of brake discs, European Structural Integrity Society, vol 29, pp.167-176, 2002, doi: 10.1016/S1566-1369(02)80073-5

[26] L. Yu, B. Ma, M. Chen, H. Li, J. Liu, M. Li, Investigation on the failure mechanism and safety mechanical-thermal boundary of a multi-disc clutch, Engineering Failure Analysis, vol. 103, pp.319-334, 2019, doi: 10.1016/j.engfailanal.2019.04.071

[27] J. Tang, D. Bryant, H. Qi, B. Whiteside, M. Babenko, Simplified three-dimensional finite element hot-spotting modelling of a pin-mounted vented brake disc: an investigation of hot-spotting determinants, Proceedings of the Institution of Mechanical Engineers, Part D: Journal of Automobile Engineering, vol. 232, iss. 7, pp. 877895, 2018, doi: 10.1177/0954407017713080

[28] Z. Yang, J. Han, W. Li, Z. Li, L. Pan, X. Shi, Analyzing the mechanisms of fatigue crack initiation and propagation in CRH EMU brake discs, Engineering Failure Analysis, vol. 34, pp. 121-128, 2013, doi: 10.1016/j.engfailanal.2013.07.004 
[29] S.P. Jung, T.W. Park, J.B. Chai et al., Thermomechanical finite element analysis of hot judder phenomenon of a ventilated disc brake system, Int J Precis Eng Manuf 12:821-828, 2011, doi: 10.1007/s12541-011-0109-5

[30] M. Kubota, T. Suenaga, D. Kazuhiro, A Study of the Mechanism Causing High-Speed Brake Judder, In: SAE Technical Paper Series, SAE International 400 Commonwealth Drive, Warrendale, PA, United States, 1998, doi: 10.4271/980594

[31] M. Kumar, X. Boidin, Y. Desplanques, J. Bijwe, Influence of various metallic fillers in friction materials on hot-spot appearance during stop braking, Wear, vol. 270, iss. 5-6, pp.371-381, 2011, doi: 10.1016/j.wear.2010.11.009

[32] X. Xu, H. Winner, Transfer behaviours and influences of high-order hot judder in passenger cars, Proceedings of the Institution of Mechanical Engineers, Part D: Journal of Automobile Engineering, vol. 232, iss. 3, pp. 400-417, 2018, doi: $10.1177 / 0954407017702995$

[33] J. Zhao, Z. Chen, H. Yang, Y.-B. Yi, Finite element analysis of thermal buckling in automotive clutch plates, Journal of Thermal Stresses, vol. 39, iss. 1, pp. 77-89, 2016, doi: $10.1080 / 01495739.2015 .1123590$

[34] M. Graf, G.-P. Ostermeyer, Hot bands and hot spots: Some direct solutions of continuous thermoelastic systems with friction, Physical Mesomechanics, vol. 15, pp. 306-315, 2012, doi: 10.1134/S1029959912030113

[35] K. Lee, J.R. Barber, An Experimental Investigation of Frictionally-Excited Thermoelastic Instability in Automotive Disk Brakes Under a Drag Brake Application, Journal of Tribology, vol. 116, iss. 3, pp. 409-414, 1994, doi: 10.1115/1.2928855

[36] P. Zagrodzki, T.D. Farris, Analysis of Temperatures and Stresses in Wet Friction Disks Involving Thermally Induced Changes of Contact Pressure, In: SAE Technical Paper Series. SAE International 400 Commonwealth Drive, Warrendale, PA, United States, 1998, doi: $10.4271 / 982035$

[37] H. Cho, C. Cho, Prediction of Hot Spots by Correlating Finite Element Analysis and Measurement for an Automotive Disk Brake, Tribology Transactions, vol. 51, iss. 5, pp.609620, 2008, doi: 10.1080/10402000802011695

[38] D.L. Hartsock, J.W. Fash, Effect of Pad/Caliper Stiffness, Pad Thickness, and Pad Length on Thermoelastic Instability in Disk Brakes, Journal of Tribology, vol. 122, iss. 3, pp. 511-518, 2000, doi: $10.1115 / 1.555394$
[39] S. Panier, P. Dufrénoy, J.F. Brunel, D. Weichert, Progressive waviness distortion: A new approach of hot spotting in disc brakes, Journal of Thermal Stresses, vol. 28, iss. 1, pp. 47-62, 2004, doi: $10.1080 / 01495730490498638$

[40] S. Panier, P. Dufrénoy, D. Weichert, An experimental investigation of hot spots in railway disc brakes, Wear, vol. 256, iss. 7-8, pp. 764-773, 2004, doi: 10.1016/S0043-1648(03)00459-9

[41] T. Schneider, K. Voelkel, H. Pflaum, K. Stahl, Friction Behavior of Pre-Damaged Wet-Running Multi-Plate Clutches in an Endurance Test, Lubricants, vol. 8, iss. 7, pp. 1-14, 2020, doi: $10.3390 /$ lubricants 8070068

[42] M. Strebel, Spontaneous damage to wet-running multi-plate clutches, $\mathrm{PhD}$ thesis, Technical University Munich, Munich, 2017. (in German)

[43] D. Thuresson, Influence of material properties on sliding contact braking applications, Wear, vol. 257, iss. 5-6, pp.451-460, 2004, doi: 10.1016/j.wear.2004.01.009

[44] D. Thuresson, Thermomechanics of block brakes, PhD thesis, Chalmers University of Technology, Gothenburg, 2006.

[45] P. Zagrodzki, S.A. Truncone, Generation of hot spots in a wet multidisk clutch during short-term engagement, Wear, vol. 254, iss. 5-6, pp. 474-491, 2003, doi: 10.1016/S0043-1648(03)00019-X

[46] W. Zhao, P. Zagrodzki, Study of Wet Friction Material Test Under Severe Thermal and Mechanical Loading ("Bump Test"), Wear, vol. 123, iss. 1, pp. 224-229, 2001, doi: $10.1115 / 1.1331056$

[47] G.J. Meingaßner, H. Pflaum, K. Stahl, Test-Rig Based Evaluation of Performance Data of Wet Disk Clutches, in 14th International CTI Symposium, 30 June 2015, Berlin, Germany.

[48] M. Hensel, H. Pflaum, K. Stahl, FVA-No. 515 I - Heft 928 - Lifetime of multi-disc clutches - Final report: Investigation of the influencing variables on the lifetime and performance limits of wet-running multi-disc clutches; definition of a method for estimating the lifetime; development of a lifetime test, Forschungsvereinigung Antriebstechnik e.V., Frankfurt/Main, 2010. (in German)

[49] H. Schiefer, F. Schiefer, Statistics for engineers, Springer Fachmedien Wiesbaden, Wiesbaden, 2018. (in German)

[50] B. Ehle, S. Lange, H.J. Trampisch, J. Windeler, Medical statistics, 2nd, revised and updated edition, Springer, Berlin, Heidelberg, 2000. (in German) 
[51] C. Karpfinger, Higher mathematics in recipes, Springer, Berlin, Heidelberg, 2015. (in German)

[52] D.J. Olive, Linear regression, Springer International Publishing, 2017.

[53] C. Dreger, R. Kosfeld, H.-F. Eckey, Econometrics, Springer Fachmedien Wiesbaden, Wiesbaden, 2014. (in German)

[54] J. Hedderich, L. Sachs, Basics from mathematics, in: Applied Statistics. Springer, pp 28-65, 2016. (in German)
[55] H.W. Lilliefors, On the Kolmogorov-Smirnov Test for Normality with Mean and Variance Unknown, Journal of the American Statistical Association, vol. 62, pp. 399-402, 1967, doi: $10.2307 / 2283970$

[56] M. Strebel, H. Pflaum, K. Stahl, Influences on the spontaneous damage of wet-running multi-plate clutches with organic friction linings, in: FVA (ed) GETLUB - Tribologie- und Schmierstoffkongress, pp 99-110, 2016. (in German) 


\section{APPENDIX A}

\begin{tabular}{|c|c|c|c|c|}
\hline \multicolumn{5}{|c|}{ Loads of step test 1 } \\
\hline Step & Differential speed in RPM & $\begin{array}{c}\text { Mass moment of inertia in } \\
\mathrm{kgm}^{2}\end{array}$ & Axial force in kN & Expected torque in Nm \\
\hline 1 & 1800 & 1.05 & 10.48 & 632 \\
\hline 2 & 2200 & 1.05 & 10.48 & 632 \\
\hline 3 & 2600 & 1.05 & 10.48 & 632 \\
\hline 4 & 2900 & 1.05 & 10.48 & 632 \\
\hline 5 & 3200 & 1.05 & 10.48 & 632 \\
\hline 6 & 3500 & 1.05 & 10.48 & 632 \\
\hline 7 & 3800 & 1.05 & 10.48 & 632 \\
\hline 8 & 4100 & 1.05 & 10.48 & 632 \\
\hline 9 & 4350 & 1.05 & 10.48 & 632 \\
\hline 10 & 4600 & 1.05 & 10.48 & \\
\hline
\end{tabular}

\begin{tabular}{|c|c|c|c|c|}
\hline \multicolumn{5}{|c|}{ Loads of step test 2 } \\
\hline Step & Differential speed in RPM & $\begin{array}{c}\text { Mass moment of inertia in } \\
\mathrm{kgm}^{2}\end{array}$ & Axial force in kN & Expected torque in Nm \\
\hline 1 & 1450 & 1.8 & 9.17 & 553 \\
\hline 2 & 1750 & 1.8 & 9.17 & 553 \\
\hline 3 & 2000 & 1.8 & 9.17 & 553 \\
\hline 4 & 2250 & 1.8 & 9.17 & 553 \\
\hline 5 & 2500 & 1.8 & 9.17 & 553 \\
\hline 6 & 2700 & 1.8 & 9.17 & 553 \\
\hline 7 & 2900 & 1.8 & 9.17 & 553 \\
\hline 8 & 3100 & 1.8 & 9.17 & 553 \\
\hline 9 & 3300 & 1.8 & 9.17 & 553 \\
\hline 10 & 3500 & 1.8 & 9.17 & \\
\hline
\end{tabular}

\begin{tabular}{|c|c|c|c|c|}
\hline \multicolumn{5}{|c|}{ Loads of step test 3 } \\
\hline Step & Differential speed in RPM & $\begin{array}{c}\text { Mass moment of inertia in } \\
\mathrm{kgm}^{2}\end{array}$ & Axial force in kN & Expected torque in Nm \\
\hline 1 & 1500 & 1,675 & 4.91 & 296 \\
\hline 2 & 1800 & 1,675 & 4.91 & 296 \\
\hline 3 & 2100 & 1,675 & 4.91 & 296 \\
\hline 4 & 2400 & 1,675 & 4.91 & 296 \\
\hline 5 & 2700 & 1,675 & 4.91 & 296 \\
\hline 6 & 3000 & 1,675 & 4.91 & 296 \\
\hline 7 & 3225 & 1,675 & 4.91 & 296 \\
\hline 8 & 3450 & 1,675 & 4.91 & 296 \\
\hline 9 & 3700 & 1,675 & 4.91 & 296 \\
\hline 10 & 3900 & 1,675 & 4.91 & \\
\hline
\end{tabular}

\begin{tabular}{|c|c|c|c|c|}
\hline \multicolumn{5}{|c|}{ Loads of step test 4 } \\
\hline Step & Differential speed in RPM & $\begin{array}{c}\text { Mass moment of inertia in } \\
\mathrm{kgm}^{2}\end{array}$ & Axial force in kN & Expected torque in Nm \\
\hline 1 & 1700 & 1.3 & 10.48 & 130 \\
\hline 2 & 2200 & 1.3 & 10.48 & 130 \\
\hline 3 & 2650 & 1.3 & 10.48 & 130 \\
\hline 4 & 3100 & 1.3 & 10.48 & 130 \\
\hline 5 & 3550 & 1.3 & 10.48 & 130 \\
\hline 6 & 3950 & 1.3 & 10.48 & 130 \\
\hline 7 & 4350 & 1.3 & 10.48 & 130 \\
\hline 8 & 4800 & 1.3 & 10.48 & 130 \\
\hline 9 & 5150 & 1.3 & 10.48 & 130 \\
\hline 10 & 5500 & 1.3 & 10.48 & \\
\hline
\end{tabular}

